\title{
ART. 145 DO CPC: DA INABILITAÇÃO DE ENGENHEIRO CIVIL PARA PROCEDER A LEVANTAMENTO AGRONÔMICO EM IMÓVEL RURAL
}

\author{
Antônio Cláudio da Costa Machado \\ Professor Assistente do Departamento de Direito Processual da \\ Faculdade de Direito da Universidade de São Paulo
}

\begin{abstract}
Resumo:
A finalidade do presente trabalho é a demonstração de que o texto do $\S 1^{\circ}$ do art. 145 do Código de Processo Civil, com a nova redação que the deu a Lei n. 8.455/92, tornou explícita a proibição de escolha, pelos juizes de direito ou federais, de profissionais não habilitados para perícias enquadráveis em atividades regulamentadas, como as que realizam os engenheiros, arquitetos ou engenheiros agrônomos sob o manto disciplinar da Lei n. 5.194, de 24.12.66, e da Resolução n. 218, de 29.06.73, do Confea, que discrimina especificamente a atuação do engenheiro agrônomo da do engenheiro civil.
\end{abstract}

\begin{abstract}
:
The target of the present work is the demonstration that the legal disposition of the $\S 1^{\circ}$ of the art. 145 of our Civil Procedure Law, with the new redaction given by the Law $n$. 8.455/92, established express prohibition that the state or federal judges nominate disqualified professionals for judicial examinations concerning activities that demand legal regulation, as those proceeded by engineers, architects or agronomic engineers under the legal discipline of the Law n. 5.194, 24.12.66, and of the Resolution n. 218, 29.06.73, of Confea, which distinguishes particularly the work of the agronomic engineer from the that one concerning the civil engineer.
\end{abstract}

\section{PARECER}

1. O parecer requerido.

Solicita-nos o doutor Jorge Augusto Lima Barreto, falando em nome da Procuradoria Geral do Estado de Sergipe, parecer jurídico tendo por objeto o questionamento relativo à validade ou invalidade de nomeação judicial de engenheiro civil, em processo expropriatório, para a realização de perícia sobre imóvel rural: levantamento agronômico com vista à implantação de projeto de irrigação para exploração de fruticultura.

Especificamente, indaga-nos o consulente nestes termos: 
"I - Até que ponto a norma vedativa da Resolução 218 , de 29.06.73 (arts. $1^{\circ}$ e $5^{\circ}$ ), que é baseada na Lei Federal n. 5.194, de 24.12.66, estende seu alcance?"

"2 - Baseado na Resolução 218/73 (Confea) o laudo pericial que é confeccionado por engenheiro civil como perito oficial é nulo ou anulável?"

"3 - Constitucionalmente, a eficácia da Lei Federal 5.194/66, que deu origem à Resolução 218/73 do Confea tem poder imperativo paritário ao Estatuto da OAB, Lei 4.215/63, no que diz respeito à vedação de funcionários públicos atuarem contra pessoas jurídicas de direito público?"

2. Observações introdutórias.

Inicialmente cumpre-nos deixar claro que as dúvidas levantadas pelo nobre consulente e colega têm caráter fundamentalmente processual, razão por que não podemos deixar de focalizar o problema apresentado, desde logo, pelo ângulo da disciplina que o Código de Processo Civil vigente estabelece para a prova pericial.

Somente depois dessa primeira e necessária abordagem, é que podemos enfrentar questões outras como as concernentes ao papel da Lei n. 5.194/66, a eficácia da Resolução n. 218/73 do Confea e sua influência sobre a atividade dos órgãos jurisdicionais no que diz respeito à nomeação de peritos.

3. As modalidades introduzidas no CPC pela Lei Federal n. 8.455/92.

Dentre as alterações introduzidas pela Lei n. 8.455/92 na disciplina da prova pericial, algumas têm direta relação com o tema que ora nos ocupa. Referimonos aos três parágrafos do art. 145, que foram criados pela Lei nova, e ao $\S$ único do art. 424, que teve sua redação remodelada. Além disso, cumpre salientar que a importantíssima regra estabelecida pelo inciso I do art. 424 (não modificada) ganhou uma nova dimensão normativa com a entrada em vigor dos $\S \S$ do art. 145. Vejamos. 
3.1. A explicitação da exigência de que o perito esteja inscrito em órgão de classe competente.

\subsubsection{Dispõe o $\S 1^{\circ}$ do art. 145 do CPC:}

" $\S 1^{\circ}$ Os peritos serão escolhidos entre profissionais de nivel universitário, devidamente inscritos no órgão de classe competente, respeitado o disposto no Capítulo VI, seção VII, deste Código."

Como se pode facilmente perceber, a intenção do legislador processual, ao criar essa nova regra, foi a de tornar exigência expressa do Código, o que a doutrina já consagrava há muito tempo, vale dizer, a necessidade de nomeação de peritos dentre os profissionais de atividades regulamentadas.

Escrevendo em 1986 - muito antes, portanto da vigência da Lei $n$. 8.455 - Vicente Greco Filho já observava:

"hoje, as profissões técnicas de nivel médio e nivel superior estão suficientemente regulamentadas por lei federal, de modo que é nesse diploma que se encontra a especialidade de cada uma" (Direito Processual Civil brasileiro, São Paulo, Saraiva, v. II, p. 211, 1986).

Tornou-se explícita e indiscutível, destarte, a partir de 1992, a proibição de escolha de profissionais não-habilitados para perícias enquadradas em atividades regulamentadas. Note-se que o $\S 1^{\circ}$ do art. 145 diz "os peritos serão" e não que eles "poderão ser".

Sobre a novel disciplina tivemos a oportunidade de comentar, um ano após a entrada em vigor da Lei n. 8.455/92, que tal disposição não tem caráter absoluto, devendo assim ser interpretada:

"porque matérias há que não correspondem a cursos e títulos universitários, e profissionais com nivel universitário há que não possuem órgãos de classe"

E concluímos: 
"a exigência desses dois elementos conjugados depende, portanto, de a perícia ter por objeto assunto tratado especificamente em curso universitário e também de os profissionais possuirem órgãos legalmente instituídos que os aglutinem" (Antônio Cláudio da Costa Machado, CPC Interpretado, São Paulo, Saraiva, p. 109, 1993).

É o caso dos engenheiros e arquitetos que têm sua profissão minuciosamente regulada pela Lei n. 5.194/66. Assim, se a perícia demanda conhecimentos técnicos em uma dessas áreas não será possível ao juiz, conforme o disposto no $\S 1^{\circ}$ do art. 145 do $\mathrm{CPC}$, nomear outro profissional que não aquele que esteja inscrito no CREA.

Com o fim de ilustrar a proibição estatuída pela lei processual, trazemos à colação a seguinte ementa:

"agravo de instrumento - Nomeação de perito sem comprovação de registro no Conselho Regional de Engenharia e Arquitetura (CREA) - Inadmissibilidade Recurso provido" (Jurisprudência Catarinense, v. 45, p. 327).

Se assim se decidia antes de 1992, por força de interpretação doutrinária, como não se decidirá hoje frente ao texto expresso do $\S 1^{\circ}$ do art. 145 do estatuto processual?

3.1.2. Outro aspecto normativo que merece realce, porque corrobora o entendimento que sustentamos, está no novo $\S 2^{\circ}$ do art. 145 que reza:

"os peritos comprovarão sua especialidade na matéria sobre que deverão opinar, mediante certidão do órgão profissional em que estiverem inscritos."

É evidente que tal comprovação só é exigida no contexto de aplicação do $\S 1^{\circ}$, isto é, na hipótese de existir profissional de nível universitário, além do órgão de classe, e surgir no curso da produção da prova pericial dúvida sobre a habilitação técnica do nomeado (neste sentido, nosso CPC Interpretado, ob. cit., p. 109, ainda). Ora, a exigência expressa de prova da habilitação em caso de dúvida 
põe às claras a vontade da lei de retirar a eficácia processual de laudo elaborado por profissional sem a devida habilitação técnica.

Neste diapasão, mais uma vez registramos que, mesmo antes de 1992, assim já entendiam nossos tribunais, verbis:

"quanto ao reclamo da autora, na parte relativa à impugnação do Assistente da ré, sob o enfoque de que o mesmo não possui a necessária habilitação para o exercício da peritagem contábil, é de se frisar que o expert comprovou encontrar-se devidamente registrado no Conselho Regional de Contabilidade de Santa Catarina, na categoria de contador, estando habilitado para o exercício da profissão de contabilista" (Jurisprudência Catarinense, v. 45, p. 236).

Inegável, portanto, a inafastabilidade da exigência de habilitação técnica, comprovável por certidão do órgão de classe, quando se trate de profissão regulamentada.

3.1.3. Por último, resta dizer alguma coisa sobre o $\S 3^{\circ}$ do art. 145 que prescreve:

"nas localidades onde não houver profissionais
qualificados que preencham os requisitos dos
parágrafos anteriores, a indicação dos peritos será de
livre escolha do juiz."

Como pudemos esclarecer no trabalho de nossa lavra já referido, este $\S 3^{\circ}$ só confere liberdade de nomeação ao magistrado na hipótese de inexistência, no território da comarca, de profissional qualificado (CPC Interpretado, ob. cit., p. 109 e 110), o que acontece, por exemplo, se não há um engenheiro inscrito no CREA para vistoriar uma ponte, ficando autorizado o juiz, para viabilizar a prestação jurisdicional, a nomear um tecnólogo ou outro profissional de sua confiança.

4. A imperatividade da Lei n. 5.194/66 e da Resolução n. 218/73 do Confea para determinar a nomeação de perito pelo juiz. 
4.1. Estabelecida a premissa de que o Código de Processo Civil, por seu art. 145, remete e vincula o juiz à regulamentação profissional pertinente no que concerne à nomeação de peritos, examinemos agora, em particular, a questão dos engenheiros.

.A Lei n. 5.194, de 24.12.66, dispõe no seu art. $2^{\circ}$ :

“art. 20: $O$ exercício, no país, da profissão de engenheiro, arquiteto ou engenheiro agrônomo, observadas as condições de capacidade e demais exigências legais é assegurado: a) aos que possuam, devidamente registrado, diploma de faculdade ou escola superior de engenharia, arquitetura ou agronomia, oficiais ou reconhecidas, existentes no pais."

Dada a necessidade de detalhamento e regulamentação das muitas atividades especializadas que compõem a engenharia e a arquitetura, e não sendo a própria Lei n. 5.194/66 a sede normativa adequada à realização desse mister, dispôs o seu art. 27:

“art. 27 São atribuições do Conselho Federal: ... f) baixar e fazer publicar as resoluções previstas para regulamentação e execução da presente lei, e, ouvidos os Conselhos Regionais, resolver os casos omissos." (grifos nossos)

Com amparo no poder que the foi conferido por lei federal, e considerando os termos genéricos em que o art. $7^{\circ}$ da Lei $n$. 5.194/66 refere-se às atividades profissionais do engenheiro, do arquiteto e do engenheiro agrônomo, o Confea baixou a Resolução n. 218, em 29.06.73, assim discriminando a atividade do engenheiro agrônomo da do engenheiro civil:

\footnotetext{
"art. $5^{\circ}$ - Compete ao Engenheiro Agrônomo: I - o desempenho das atividades 01 a 18 do art. $1^{\circ}$ desta Resolução referente a engenharia rural; construções para fins rurais e suas instalaçôes complementares; irrigação e drenagem para fins agrícolas; fitotecnia $e$ zootecnia; melhoramento animal e vegetal; recursos naturais renováveis; ecologia ... química agrícola;
} 
alimentos ... edafologia ... processo de cultura e de utilização do solo ..." (grifos nossos)

"art. $7^{\circ}$ - Compete ao Engenheiro Civil ou ao Engenheiro de Fortificação e Construção: I - o desempenho das atividades 01 a 18 do art. $1^{\circ}$ desta Resolução referente a edificações, estradas, pistas de rolamentos e aeroportos, sistemas de transportes, de abastecimento de água e de saneamento; portos, rios, canais, barragens e diques; drenagem e irrigação; pontes e grandes estruturas; seus serviços afins $e$ correlatos."

Note-se, para o fim que nos ocupa, que a atividade 06 do art. $1^{\circ}$ da Resolução vem assim discriminada:

\section{"Atividade 06 - vistoria, perícia, avaliação, arbitramento, laudo e parecer técnico"}

Discorrendo sobre os limites ao poder de regulamentar, assim se manifesta Oswaldo Aranha Bandeira de Mello, verbis:

“... o regulamento tem limites decorrentes do direito positivo. Deve respeitar os textos constitucionais, a lei regulamentada, e a legislação em geral, e as fontes subsidiárias a que ela se reporta." E segue: "Ademais, sujeita-se a comportas técnicas. Assim, não cria, nem modifica e sequer extingue direitos e obrigações, senão nos termos da lei, isso porque o inovar originariamente na ordem jurídica consiste em matéria reservada à lei."

Quanto à titularidade da atribuição regulamentar assevera Bandeira de Mello:

"além deles (o Legislativo e o Judiciário), as entidades político-administrativas menores $e$ as autarquias de serviços ou estabelecimentos públicos exercem ditas prerrogativas, para efeito de aplicação das leis que regulam a sua organização e ação." (Principios Gerais 
de Direito Administrativo, $2^{\mathrm{a}}$ ed., Rio, Forense, v. I, pp. 360-2, 1979).

Ora, em face do claro teor da lição do mestre, não resta nenhuma dúvida de que o Conselho Federal de Engenharia, Arquitetura e Agronomia (Confea), como autarquia federal que é, tem poder regulamentar ex vi legis para dizer o que cabe a cada categoria de engenheiro fazer ou não-fazer (art. 27, "f", da Lei Federal n. 5.194/66). Destarte, o que o Confea determina em sua Resolução $n$. 218/73 evidentemente vincula o juiz de direito ou federal no que concerne à prática do ato de nomeação de perito, haja vista a prescrição contida no art. 145 e seus $\S \S$ do CPC.

4.2. Voltando nossos olhos agora, especificamente, para o disposto nos arts. $5^{\circ}$ e $7^{\circ}$ da Resolução n. 218/73 do Confea, parece-nos bem fácil sustentar 0 enquadramento da situação concreta apresentada na primeira previsão (engenheiro agrônomo) e não na segunda (engenheiro civil) e isso por algumas razões: a. pelo menos em sede de princípio, o levantamento agronômico em imóvel rural insere-se na engenharia rural; b. o escopo do levantamento proposto é a verificação da viabilidade da implantação de um projeto de irrigação; $c$. a finalidade do possível projeto de irrigação é permitir a exploração da fruticultura, que é fim agrícola, de caráter alimentar, depende de conhecimentos de edafologia (ciência que estuda os solos), e se identifica com processo de cultura e de utilização do solo (v. texto do art. $5^{\circ}$ que reproduzimos, em parte, no item 4.1.).

Em suma, ainda que desprovidos de formação técnica de engenharia, ousamos afirmar que o levantamento agronômico de imóvel rural para fins de projeto de irrigação não se encaixa na competência de engenheiro civil, de acordo com os artigos mencionados da Resolução n. 218 do Confea. 
5. A falta de conhecimento técnico do engenheiro para realizar perícia fora de sua área de especialização. A doutrina processual. A jurisprudência.

5.1. Comentando o inciso I do art. 424 do CPC, cujo teor normativo foi reforçado pelas modificaçðes introduzidas no art. 145, tivemos a possibilidade de ensinar que:

"a falta de conhecimento técnico ou científico torna a prova pericial, formalizada no laudo, absolutamente inidônea para a demonstração do fato litigioso. Logo, o juiz deve valorá-la dessa maneira (art. 131), quer porque a parte o requereu, quer de oficio. A carência de conhecimento especializado deve estar suficientemente comprovada para que o magistrado a reconheça, não se podendo perder de vista que conhecimento técnico não é sinônimo de diploma universitário (pode ser se a lei expressamente o exigir, como v. g., nos casos dos engenheiros, arquitetos, médicos, psicólogos)" (CPC Interpretado, ob. cit., p. 362).

Visto que no caso dos engenheiros, o conhecimento técnico exigido pelo CPC (art. $145, \S \S 1^{\circ}$ e $2^{\circ}$ ) deve necessariamente se expressar no registro formal no CREA (Lei n. 5.194/66, art. $2^{\circ}$, "a" e $\S$ único), e numa habilitação específica nos termos da Resolução n. 218/73 do Confea (arts. $1^{\circ}$ a 22), resta-nos examinar como a doutrina e a jurisprudência tem encarado este último aspecto normativo.

5.2. Antes de mais nada, é necessário ressaltar que o perito há de ser um profissional especializado na área em que se exige a sua intervenção, há de possuir capacitação técnico-científica particularizada num determinado ramo do conhecimento humano (neste sentido, José Frederico Marques, Manual de Direito Processual Civil, $2^{\mathrm{a}}$ ed., São Paulo, Saraiva, v. II, p. 227, 1976; Vicente Greco Filho, ob. cit., v. II, p. 211).

Esta singela circunstância processual, por si só, já justificaria o reconhecimento da autoridade do Conselho Federal de Engenharia, Arquitetura e Agronomia (Confea), para declarar que categoria de engenheiro pode realizar um levantamento agronômico em imóvel rural. 
Sob o ponto de vista da especialização do profissional, muito apropriada se nos afigura a lição de Ernane Fidelis dos Santos, cujas palavras tomamos a liberdade de transcrever:

"há perícias que só devem ser feitas por profissionais habilitados, como ocorre com o engenheiro, inclusive $o$ agrônomo, o médico e o contador ... A falta de conhecimento técnico pode ser verificada a qualquer momento e no correr da própria perícia. O neurologista pode até ter conhecimentos psiquiátricos mas se, ao iniciar os trabalhos, verificar que o caso exige conhecimento mais especializado, deve declinar da perícia para o especialista" (Manual de Direito Processual Civil, São Paulo, Saraiva, v. 2, p. 159, 1986).

O exemplo apresentado por Fidelis dos Santos é extremamente feliz para ilustrar o entendimento que vimos sustentando: da mesma forma como não pode um médico neurologista oferecer laudo pericial a respeito de fatos que demandem conhecimentos psiquiátricos (próprios do médico psiquiatra), não pode um engenheiro civil realizar levantamento agronômico em imóvel rural para fins de implantação de projeto de irrigação, matéria própria do engenheiro agrônomo. O paralelo é perfeito porque também na medicina as especialidades são muitas e a formação acadêmica e curricular de um especialista muitas vezes não tem nada, ou muito pouco, a ver com outra. Qual de nós submeteria a um cardiologista um caso de fratura exposta de perna? O raciocínio vale para a perícia agronômica que nos ocupa. Tome-se outro paradigma, agora jurisprudencial. Há alguns anos se decidiu que:

\footnotetext{
"engenheiro topográfico não tem conhecimento técnicocientífico para realizar perícia mecânica em máquina de terraplanagem" (Revista dos Tribunais, v. 506, p. 255).
}

A idéia é a mesma. Não basta ser formado em engenharia e nem possuir registro no CREA para que um profissional esteja habilitado para qualquer espécie de exame, vistoria ou avaliação judicial. Só estará habilitado para uma perícia mecânica o engenheiro mecânico nos termos do art. 12 da Resolução $n$. 218/73 do Connfea. 
A falta de conhecimento técnico de engenheiro civil para um levantamento agronômico em imóvel rural é tão flagrante quanto o de um topógrafo para perícia mecânica em máquina de terraplanagem, como a de um neurologista para o exame de alguém que sofra problemas psiquiátricos como nos ensina Fidelis dos Santos.

Em qualquer desses casos a solução processual será uma e somente uma:

"é inidônea a prova se o perito não tem conhecimento
técnico necessário à elaboração do laudo" (RTJ 83/964,
$1^{\mathrm{a}}$ col.) (o acórdão é citado por Theodoro Negrão, in
CPC e legislação processual em vigor, $17^{\mathrm{a}}$ ed., São
Paulo, RT, p. 197).

6. Conclusões. Respostas às indagações formuladas.

Examinado o caso concreto que nos foi apresentado sob os enfoques do Código de Processo Civil, da Lei n. 5.194/66, da Resolução do Confea n. 218/73, falta-nos apenas responder objetivamente aos questionamentos formulados pelo consulente, doutor Jorge Augusto Lima Barreto, o que passamos a fazer nos seguintes termos:

1. À primeira indagação, respondemos que a Resolução n. 218/73 (corpo de regras regulamentadoras das atribuições das várias categorias de engenheiros) vincula de forma absoluta o juiz de direito, ou federal, no que concerne à nomeação de engenheiro, arquiteto ou agrônomo para perícias judiciais. A sujeição do órgão jurisdicional aos ditames normativos da Resolução n. 218/73 acontece por duas razões: a. porque tal resolução representa o instrumento formal pelo qual o Confea (Conselho Federal de Engenharia, Arquitetura e Agronomia) regulamentou a Lei n. 5.194/66 que estabelece a necessidade de disciplina do exercício dessas profissões; b. porque o CPC, por seu art. $145, \S \S 1^{\circ}$ e $2^{\circ}$ exige a nomeação de profissional de nível universitário devidamente inscrito no órgão de classe competente, o que significa, no caso dos engenheiros, que a lei processual remete o juiz à Lei n. 5.194/66 e seu regulamento, a Resolução n. 218/73.

2. À segunda indagação, respondemos fazendo uma distinção: a nomeação de engenheiro civil para uma perícia que exige engenheiro agrônomo (ex 
vi do disposto no art. $5^{\circ}$ da Resolução n. 218/73 do Confea) permite à parte impugná-lo e pedir a sua substituição por falta de conhecimento técnico e ao juiz reconhecer tal circunstância de ofício, determinando a substituição (CPC, art. 424, I). Quanto ao laudo oferecido por perito não-habilitado - porque não-substituído a tempo de ofício ou a requerimento da parte - tal documento é inidôneo, como tem decidido nossos tribunais, para gerar convencimento do juiz sobre o fato litigioso (CPC, art. 131).

3. À terceira e última indagação respondemos que embora não exista na Lei n. 5.194/66 nenhuma regra semelhante à prevista pelo inciso VI do art. 85 do Estatuto da $\mathrm{OAB}$ - que declara impedido de exercer a advocacia contra as pessoas jurídicas de direito público em geral quem seja servidor público - o Código de Ética do Engenheiro, Arquiteto e Engenheiro Agrônomo (Resolução n. 205, de 30.09.71, do Confea) dispõe no seu art. $7^{\circ}$, letra "e":

"art. $7^{\circ}$ - Exercer o trabalho profissional com lealdade, dedicação e honestidade para com seus clientes $e$ empregadores ou chefes, e com espirito de justiça e eqüidade para com os contratantes e empreiteiros.

Em conexão com o cumprimento deste artigo, deve o profissional: ...

e) não-praticar quaisquer atos que possam comprometer a confiança que lhe é depositada pelo seu cliente ou empregador."

Dada a normatividade da prescrição acima transcrita é lícito afirmar que um engenheiro que tenha vínculo funcional ou empregatício com uma pessoa jurídica não pode funcionar como perito em causa em que esta figure como parte.

Era o que nos parecia conveniente declarar acerca da consulta formulada. 